\title{
Metodologia da interpretação adaptada ao desenvolvimento de projeto de móveis planejados
}

\section{Methodology of interpretation adapted to the development of planned furniture design}

Quetelim Andreoli Teixeira ${ }^{[1]}$, Alexandre Vergínio Assunção ${ }^{[2]}$ (orientador)

\begin{abstract}
Resumo: O tema central deste trabalho é a discussão a respeito da articulação simbólica, levando em conta o design emocional, a hermenêutica profunda e a imaginação ativa no processo de criação de projetos de móveis planejados modulares. Em um primeiro momento, fez-se um aparato sobre conceitos-chave do design e autores que validassem a fala sobre um assunto que aborda um universo de difícil mensuração. Posteriormente, passou-se a um estudo teórico sobre as conceituações de móveis planejados modulares. Em seguida, adaptou-se ao processo de criação ao método da hermenêutica profunda de Thompson com o auxílio da teoria de articulação simbólica de Beccari. Por fim, explanou-se a metodologia obtida. Os resultados apontaram para a importância desde método que considera tanto os aspectos funcionais quanto os emocionais durante o desenvolvimento do projeto.
\end{abstract}

Palavras-chave: Design de Móveis Planejados. Metodologia. Articulação Simbólica. Design Emocional. Imaginação Ativa. 


\begin{abstract}
The central theme of this work is the discussion about the symbolic articulation, taking into account the emotional design, the deep hermeneutics and the active imagination in the process of creating modular furniture designs. At first, an apparatus was made on key concepts of design and authors that validated speech on a subject that addresses a universe of difficult measurement. Subsequently, a theoretical study was carried out on the concepts of modular modular furniture. He then adapted to the process of creation to Thompson's method of deep hermeneutics with the help of Beccari's symbolic articulation theory. Finally, the methodology was explained. The results pointed to the importance of a method that considers both functional and emotional aspects during project development.
\end{abstract}

Keywords: Design of Planned Furniture. Symbolic Articulation. Emotional Design. Active Imagination.

\title{
INTRODUÇÃO
}

O problema gerador deste trabalho é o questionamento sobre como podemos interpretar e significar ambientes domésticos, para que estes sejam contemplados com as experiências e anseios dos usuários requerentes do projeto, utilizando a modulação de móveis planejados.

O conceito de articulação simbólica tem o sentido aqui de colocar-se no lugar do outro para compreendê-lo melhor. No design, o outro é o sujeito que solicita o projeto de algo, colocando em evidência suas necessidades e vontades. A ideia de articular, no design, é colocada aqui como a tentativa de compreender e explicar essas vontades, necessidades e expressões desse sujeito. Segundo Norman (2008, p. 62), "as vontades são determinadas pela cultura, pela publicidade, pela maneira como a pessoa vê a si mesma e sua autoimagem [...] os designers sabem que vontades podem ser mais poderosas que as necessidades na determinação do sucesso de um produto". Assim, a articulação simbólica, neste trabalho, tem a aspiração de compreender o desejo e a necessidade do outro.

Já o design emocional, tratado por Norman (2008), tem também foco na simpatia ou no ódio que temos pelos objetos.

Além da forma física e funções mecânicas, os objetos assumem 'forma social' e 'funções simbólicas' [...] os designers voltam sua atenção para as pessoas e o modo como 
elas interpretam e interagem com o meio físico e social. E passam a projetar com foco na 'emoção' e com a intenção de proporcionar experiências agradáveis (NORMAN, 2008, p. 11).

Sendo assim, averigua-se de que forma pode-se recuperar o "laço" da razão e da sensibilidade no processo de projeto de móveis modulados adaptando um método existente para as peculiaridades do tema.

Atualmente, existe o que se chama de "móveis planejados modulares", produto da indústria moveleira que caminha em conjunto com o design de móveis e com o design de interiores. Este ramo da indústria consiste em produzir partes - ou módulos - com padrões predefinidos de tamanhos e modelos, que deverão, posteriormente, ser organizados por um profissional, de acordo com aspectos funcionais, estéticos e simbólicos. Como explica Löbach (2001, p. 55) "no processo de configuração de produtos industriais, o projetista e o designer industrial devem otimizar as funções de um produto visando satisfazer as necessidades (e as vontades) dos futuros usuários". Os móveis planejados modulares são uma categoria de móveis retilíneos seriados (GORINE, 2000), como podemos ver na figura 01. Esses grupos de móveis retilíneos têm, por objetivo principal, preencher o espaço de um ambiente da melhor maneira possível, ocupando cada centímetro do ambiente que está sendo projetado, no entanto, há sutis diferenças entre eles.

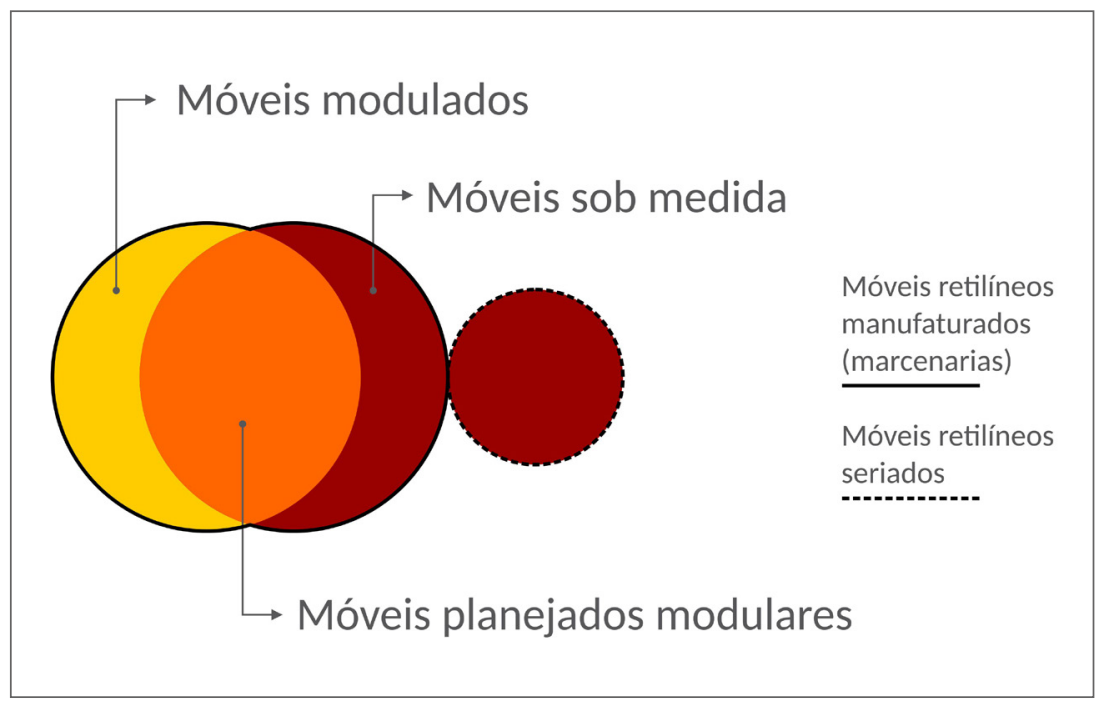

Figura 1: Esquema de tipos de móveis retilíneos. Fonte: Produção da autora, 2018. 
Os Móveis Modulados são móveis divididos em módulos predefinidos por uma fábrica, que, já possuem um ou mais padrões de tamanho e modelo. As opções oferecidas para o cliente diferem de fábrica para fábrica, levando em consideração também o público alvo - classe social. Esse panorama das classes sociais e o comportamento da indústria brasileira pode ser entendido a partir da explicação de que:

A indústria aparece a partir da classe A, na qual o modelo de negócio predominante é o de móveis planejados: nesse caso, o consumidor vai a uma loja, onde um profissional especializado lhe propõe uma solução funcional e estética que, respeitadas as possibilidades existentes no catálogo da empresa, tenta oferecer um produto personalizado. Esse é também o modelo que predomina na classe B, embora com produtos que começam a buscar certo equilíbrio entre custo e benefício, normalmente sacrificando mais o luxo do que a qualidade dos componentes. É na classe C que o equilíbrio entre custo e benefício assume o papel central na decisão de compra, e é aqui que as lojas de móveis seriados (ou seja, produzidos em larga escala, sem personalização) começam a dividir espaço com o segmento de móveis planejados. A partir da classe $\mathrm{D}$, o modelo de móveis planejados se torna de difícil sustentabilidade, cedendo espaço não só ao pulverizado varejo das lojas especializadas quanto às grandes redes varejistas, como Casas Bahia e Magazine Luiza, que por sua vez também tentam atender tanto ao segmento D, E quanto ao C e, eventualmente, ao B (GALINARI at al., 2013, p. 250).

Os Móveis planejados podem ou não ser modulares. Há inúmeras fábricas de modulados que, com o intuito de alcançar um produto final de excelência, acabam por oferecer, com o passar do tempo, muitos módulos diferentes e, à medida que se aperfeiçoam no segmento e ganham mercado, acabam disponibilizando peças editáveis. Este fato reclassifica a manufatura (marcenarias) em fábricas de móveis planejados (GORINE, 2000).

Algumas fábricas disponibilizam módulos inteiros editáveis, outras, apenas algumas peças lineares, onde uma ou mais dimensões podem ser editadas. Isso que pode parecer uma diferença irrisória é fundamental para fazer os acabamentos dos ambientes projetados, sem contar que essas 
peças editáveis possibilitem que situações diferenciadas possam ser propostas, dando aos projetos características únicas.

É na hora de fazer a articulação das características de um ambiente - estas que devem ser personificadas de acordo com o usuário - que se observa uma carência por parte dos projetistas. Essa insuficiência nos aspectos emocionais é uma herança da carga funcionalista que a maioria dos produtos seriados carrega (LÖBACH, 2001).

O estudo da dinâmica do pensamento no processo criativo serve para entender e compilar o método de Thompsom (2011) a fim de melhorar a prática do design nesta área. Este método juntamente da teoria de Beccari fornecerá subsídios teóricos para que surjam novas possibilidades para a interpretação e significação do que se está produzindo. Passa-se ao estudo, compilação e explanação dos estudos feitos.

\section{A DINÂMICA DO PENSAMENTO NO PROCESSO CRIATIVO}

No mundo em que se vive hoje, de atividades massivas e de global imediatismo, tão comum são as pessoas conduzidas pela produção seriada. Em decorrência da velocidade a qual a sociedade é submetida diariamente, observa-se, com frequência, o design sendo agente remediador dos efeitos da herança funcionalista - dando formas atraentes à função, tratada como característica mais importante, deixando de lado os aspectos emocionais e reflexivos do objeto ou ambiente durante o processo criativo (COLLET, DISCHINGER, KINDLEIN JUNIOR, 2008).

Norman (2008) colabora com a ideia de que não importa tanto a estética ou a função de algo, importa se o objeto dá prazer, se faz sentido e se a experiência com o objeto significou algo na nossa vida. Assim sendo, o modo como encaramos o experimento define o nosso (incluindo o designer como usuário), lugar na sociedade e no mundo.

É necessário pesquisar o que não está dado, o que não é fato, para que se possam projetar objetos melhores. Os preceitos do funcionalismo estão cada vez mais sendo questio- 
nados. Os ensinamentos do arquiteto norte americano Louis H. Sullivan (1856-1924), que globalizou com a máxima funcionalista de que "a forma segue a função", não comportam os anseios da sociedade atual (COELHO, 2011).

Entende-se melhor o que se chamou de "fato" no parágrafo anterior com a definição de Langer (1989, p. 265) que qualifica o termo como "concepção ancorada na realidade". Neste trabalho se usará "fato" para representar aquilo de que não se tem dúvidas: os dados mensuráveis. Neste contexto, Bonsiepe se faz categórico ao afirmar que:

Com relação à pesquisa em design, deve-se reservar um espaço maior para atividades teóricas. A teoria vai além do que tem sido até agora, quando se limita apenas à aplicação imediata, sofrendo de um estreitamento do horizonte e de uma atrofia da consciência especulativa (BONSIEPE, 2011, p. 233).

Outro autor, que é ainda mais específico e aproxima a crítica de Bonsiepe à esfera deste trabalho: Beccari (2012, p. 298) que afirma que "do ponto de vista da Articulação Simbólica, esta 'inambiguidade' (não tem ambiguidades, busca por dados objetivos) do funcionalismo parece um esforço injustificado que culmina em um empobrecimento de sentido".

Para adequar o processo de design para um âmbito que dê conta dos três aspectos de um objeto com igual importância - estético, funcional e simbólico - discorre-se neste texto a tentativa de aproximar a tese de Beccari (2012) sobre Articulações Simbólicas com a de Thompson (2011), sobre o Referencial metodológico da hermenêutica de profundidade ao setor que projeta móveis planejados.

Beccari (2012) fornece subsídio para focar na etapa do processo criativo que permite ao designer pensar empaticamente. Possibilita assim, gerar interpretação e significação para o que se está produzindo, estando centrado não apenas na experiência pessoal, mas nos anseios e afetos do usuário. Para explicar algo a alguém, precisa-se antes compreender o que queremos explicar. Para a compreensão e interpreta- 
ção de dados, a reflexão de Thompson (2011) é fundamental, porque se enriquece com a hermenêutica de profundidade que vai tratar da interpretação das simbologias através de arquétipos sociais contextualizados.

O ser humano é falho ao tentar se colocar no lugar do outro para sentir o que este outro sente. No ramo de design de móveis planejados não se pode simplesmente propor um teste ao usuário ou mesmo colocar-se dentro da rotina e casa do cliente para entendê-lo melhor. Por isso que a articulação simbólica no âmbito projetante, com respeito e empatia pelas expressões do outro, é tão importante neste trabalho.

A empatia é o hábito mental que nos leva a pensar nas pessoas como pessoas. E não como ratos de laboratório ou desvios-padrão. Se formos "tomar emprestada" a vida dos outros para inspirar novas idéias, precisam começar reconhecendo que seus comportamentos aparentemente inexplicáveis representam diferentes estratégias para lidar com o mundo confuso, complexo e contraditório no qual as pessoas vivem (BROWN, 2010, p. 46).

Na passagem de Brown, fica aparente que no design não nos referimos à empatia apenas como um afeto positivo, mas como define Nicola (2012), empatia é o comportamento humano de imitar e projetar. O fato de reproduzir as manifestações corpóreas alheias (devido ao instinto de imitação) reproduz as mesmas emoções que deveriam acompanhá-las, colocando o imitador no estado emotivo da pessoa a quem essas manifestações pertencem.

Para trilhar o caminho onde se ressalta este olhar da articulação criativa, antecipa-se, à filosofia de Beccari e ao método de Thompson, os conceitos do Design Emocional, que se propõe a organizar em três aspectos a percepção humana, portanto, trata da afetividade da relação objeto-humano em três níveis, que serão definidas no item a seguir. 


\section{DESIGN EMOCIONAL}

Para entender o que é o Design Emocional é importante observar como se lida com os objetos ao nosso redor. Norman (2008) dá o exemplo da sua coleção pessoal de bules de chá, três modelos que ilustram diferentes aspectos de design, são eles: o visceral, referente à aparência, o comportamental que considera o prazer e a afetividade de uso e o reflexivo que diz respeito à racionalização e a intelectualização de um produto.

O que o autor quer salientar com essas três categorias é que o designer é capaz de conceber objetos que irão além da sua forma física. Os artefatos são capazes de desencadear emoções e cognições através de diferentes dimensões que se apresentam entrelaçadas em seu design. Portanto, existe um componente cognitivo e um componente afetivo, onde o cognitivo concede significado e o afetivo concede valor ao que as pessoas fazem, adquirem, respondem, etc.

As emoções interpretadas pelas pessoas relativas às suas experiências podem ser explicadas de diferentes formas. O que agrada a um pode não agradar a outro , o que requer ser ainda mais exigentes quanto ao trabalho de significação de um símbolo a partir das percepções que pertencem ao nível da psique.

Apesar de parecerem estar em posições distintas, antagônicas, "as emoções são inseparáveis da cognição" (NORMAN, 2008, p.27), o autor ainda fala que mesmo sendo reconhecível a importância das características funcionais de um objeto "o lado emocional do design pode ser mais decisivo para o sucesso de um produto que seus elementos práticos".

Norman (2008) define os níveis como:

a) O design visceral está relacionado ao impacto emocional imediato - aparência;

b) No design comportamental a função vem em primeiro lugar e é o mais importante. Os quatro componentes que mais importam são a função, a compreensibilidade, a usabilidade e a sensação física;

c) O design reflexivo cobre um território muito vasto. Este diz respeito à autoimagem e às mensagens que um produto 
envia às outras pessoas. Os sentimentos de prestígio, percepção de raridade e de exclusividade operam neste nível.

Visto a definição dos três níveis de design, entende-se que apesar do design visceral ter um papel estimável num primeiro contato da experiência simbólica e se impressionar com a novidade do objeto e do design comportamental que avalia se o objeto funciona e é utilizável de fato, o nível que interessa ao proponente da criação emocional é o design reflexivo.

É com o domínio do design reflexivo que se compreenderá como dar a interpretação da forma significada para o mundo. Haja vista que a vivência da experiência simbólica tem mais efeito/intensidade que o que é fato no processo de articulação simbólica.

\section{EXPERIÊNCIA SIMBÓLICA}

A experiência simbólica segundo Beccari (2012) é uma espécie de instância mediadora entre o consciente e o inconsciente, entre o oculto e o revelado. A dificuldade em definir e, portanto, entender do que se está falando, provém da origem da experiência simbólica que nada mais é que uma energia psíquica em fluxo constante.

Outros autores como Barreto (2008) falam em algo semelhante, chamam de atividade espiritual fundamental a possibilidade das realizações humanas tornarem-se obras de cultura. Essas realizações se fazem possíveis através do que ele chama de "força espiritual peculiar", essa força, nada mais é do que a própria imaginação.

A detenção da imaginação pelo ser humano é o que torna possível que se faça as conexões necessárias para desvendar e agregar a dualidade nos espectros de conflito cotidiano. São essas polarizações da vida real que afetam através da experiência simbólica. São as dicotomias entre os anseios, crenças, conduta, modus vivend e sentimento, que amplificam os efeitos das vivências em nosso íntimo. 
Como abarca-se o conceito de imaginação, cabe definir que para este trabalho interessa o que diz respeito à imaginação criadora, a explicação:

Distingue-se [...] por sua autonomia, por aquilo que Gaston Bachelard chama de função de realização, mediante a qual ela transgride o jugo da realidade e lê a natureza como uma fisionomia humana móvel [...] podemos dizer que a imaginação criadora humana vem substituir o fechamento do vínculo instintivo por uma abertura projetante (BARRETO, 2008, p. 15).

Ostrower (1986, p. 32) também utiliza conceitos que tangenciam a teoria de Barreto, a autora cita o conceito de imaginação criativa que seria um levantamento "de hipóteses sobre certas configurações viáveis a determinada materialidade. Assim o imaginar seria um pensar específico sobre um fazer concreto". Beccari (2012, p. 341) acrescenta a definição de imaginação criadora que "no design configura um contínuo fluxo comunicacional 'em aberto' e não um caminho unidirecional voltado à autocompreensão individual".

Esses conceitos levam a entender melhor o que é e como se dá a experiência simbólica, no entanto para este trabalho importa a própria experiência e as significações que ela explicita para o indivíduo mediador. Para se mergulhar, ainda mais, na compreensão do mundo pelas significações das formas, passa-se para o método oriundo da intersecção da vertente de Beccari e de Thompson.

\section{METODOLOGIA DA INTERPRETAÇÃO COM ARTICULAÇÃO SIMBÓLICA: MÉTODO DE DESENVOLVIMENTO DO PROJETO}

O "como" desenvolver um projeto de móveis planejados, que tenha igual ênfase nos aspetos funcionais e simbólicos trata-se do desdobramento da articulação simbólica no processo de criação de um projeto, sabido que, em geral, os aspectos simbólicos são tratados com menor ênfase por metodologias clássicas (principalmente quando seguem um viés funcionalista). 
Para tal, utiliza-se uma adaptação da Metodologia da interpretação, do autor Thompson (2011), que utiliza a tradição específica de pensamento chamada hermenêutica, e como o trabalho do autor é baseado em Paul Ricoeur, trata-se aqui do referencial metodológico da hermenêutica de profundidade.

Em geral, o valor deste método é dado, pois:

Possibilita desenvolver um referencial metodológico que está orientado para a interpretação (ou reinterpretação) de fenômenos significativos, mas em que os diferentes tipos de análise podem desempenhar papéis legitimados e que se apoiem reciprocamente (THOMPSON, 2011, p. 33).

A metodologia da interpretação desenvolve a Hermenêutica de Profundidade (HP) em um referencial teórico que compreende três fases, são elas: (a) análise sócio-histórica; (b) análise formal discursiva e (c) interpretação (ou reinterpretação) (THOMPSON, 2011). Para adaptar a HP no processo de criação de móveis planejados se adicionará uma fase, a qual se nomeou de (d) executiva. Fechando assim o ciclo que compreende o desenvolvimento de projeto.

Outras aproximações foram feitas, e podem ser acompanhadas na figura 02 , onde se trouxe a HP para o âmbito do processo de projeto do móvel planejado. Thompson (2011) entende que as etapas da HP não possuem uma ordem, podendo ser aplicada em uma compreensão com as etapas em diferentes configurações, no entanto, para este trabalho, consentiu-se a fluidez entre as etapas, mas, elas precisam seguir uma cronologia, porque a coleta de dados, no início, é imprescindível para a evolução das etapas seguintes.

O autor descreve as etapas da seguinte forma: (a) Análise sócio-histórica: "está interessada nas condições sociais da produção, circulação e recepção das formas simbólicas". (b) Análise formal discursiva: serve para "estudar as formas simbólicas como construções simbólicas e complexas que apresentam uma estrutura articulada", (c) Interpretação (ou reinterpretação): "essa fase interessa-se pela explicitação criativa do que 
é dito ou representado pela forma simbólica. Analisa a construção criativa de um possível significado" (THOMPSON, 2011).

Para a adaptação do método, entende-se que, as três etapas da HP seguirão, ainda que com fluidez cronológica, a sequência descrita na figura 02, acompanhada pela última etapa executiva.

Articulação simbólica

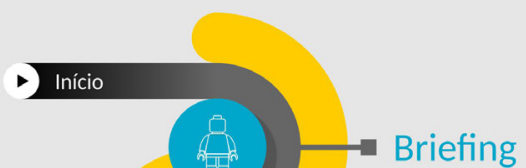

Levantamento

quantitativo

Reunião dos dados métricos, que são fatuais.

Etapa reflexiva. Processo imaginativo e significação de forma. Momento de compreensão do outro e do contexto. Valorização da forma e da explicação da imagem da imaginação para o mundo real. Traduzindo a imagem abstrata em croqui, esboço, desenho.

Projeto executivo Elaboração de dados para a plena execução do projeto. Representação técnica.

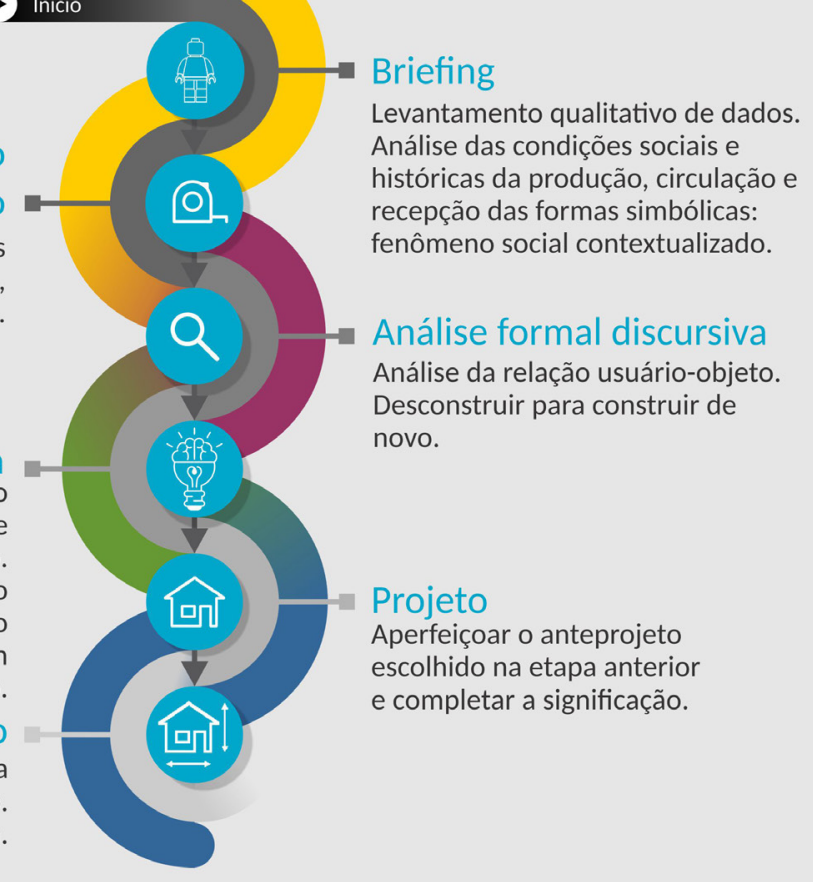

Análise sócio-histórica
$\begin{aligned} & \text { Interpretação } \\ & \text { (ou reinterpretação) }\end{aligned}$

Na primeira etapa (representada pela cor amarela), a da análise sócio-histórica, serão colhidos os dados referentes aos usuários do ambiente, sua idade, profissão, condições sociais em geral, gostos culturais, referências. Dados da localização,

Figura 2: Metodologia da interpretação com articulação simbólica. Fonte: Adaptado de Beccari (2012) e Thompson (2011) pela autora, 2018. 
onde os proponentes do projeto moram, também são relevantes nesta etapa. Deve ainda, ser feito o levantamento quantitativo do ambiente em questão: medidas in loco, especificações dos eletrônicos, a tabela que a fábrica dispõe de modulação fixa e editável, inclusive a pretensão financeira para aquisição do projeto.

Na segunda fase (representada pela cor rosa), a análise formal discursiva, compreende principalmente a etapa de problematização, pois se propõe a analisar por alguma teoria, seja ela semiótica, de conversação, sintática, narrativa ou pela argumentativa. Essa análise acaba sendo feita pelo profissional à medida que este toma conhecimento das formas simbólicas específicas, que pertencem à relação humano-objeto, do seu cliente. Por esse motivo, representam-se as cores das etapas em tons de degrade, pois o processo não tem, necessariamente, uma delimitação exata.

Na sequência, passa-se a etapa de cor verde, a interpretação (ou reinterpretação). Essa etapa trata de "costurar" os significados no movimento interpretativo e naturalmente, se constitui em paralelo com as duas etapas anteriores. Contudo, entende-se que apenas a instrução do pensamento hermenêutico de Thompson não dará conta sozinha do processo. Portanto, desdobra-se esta etapa do processo, utilizando a teoria da imaginação ativa do autor Beccari (2012) como complemento. O desdobramento da terceira etapa será mais bem explicado no item "Articulação Simbólica" deste trabalho.

Por fim, se tem a etapa executiva (cor azul). Essa etapa compreende o aperfeiçoamento do resultado obtido na etapa anterior, gerando a representação de forma gráfica para que a ideia criativa possa ser difundida de forma visual para os clientes. Outro ponto desta etapa é a geração do projeto executivo que envolverá as pranchas técnicas ou listagem de peças para a produção e o manual de montagem do projeto.

Como mencionado anteriormente, pretende-se com este trabalho, se aproximar, o máximo possível, de uma metodologia que tenha uma real preocupação com a parte emocional de 
um projeto. Foi descrito neste item do texto o processo adaptado de Thompson, como um todo. Passa-se então, para o próximo item, que traz considerações do desdobramento da terceira etapa, a teoria do autor Beccari sobre articulação simbólica.

\section{ARTICULAÇÃO SIMBÓLICA}

A articulação simbólica, segundo Beccari (2012), é uma espécie de instância mediadora entre o inconsciente e o consciente. Metaforicamente comporta-se como um "médium" entre o sujeito e o objeto, entre a imanência e a transcendência do mundo, como uma corrente elétrica invisível que se transforma em um painel de neon luminoso. A criatividade também é invisível, mas através da transferência dessa energia do meio orgânico, para o meio real, pode dar formas objetivas a intuições subjetivas.

Para essa "geração da forma", Beccari traz noções de símbolo, pois, o processo de articulação simbólica é gerador, por assim dizer, de novos símbolos. Assim sendo, compreende-se que símbolo pode ser "a melhor descrição ou formulação possível, naquele momento, de um fato relativamente desconhecido (...) que, por isso mesmo, (...) não pode ser meIhor representado" (JUNG, 1991, p.443 apud BECCARI 2012, p. 215). Complementa-se com Nordby (2005, p.103) com a fala de que o símbolo é "uma tentativa de elucidar através da analogia, algo ainda pertencente inteiramente ao domínio do desconhecido, ou de alguma coisa que ainda virá a ser" (apud BECCARI 2012, p. 215).

A noção de símbolo se faz necessária, pois, neste estudo as relações entre o sujeito e símbolo serão importantes. Principalmente a relação que acontece "através do diálogo consciente, isto é, com uma interpretação posterior, mas sem reduzir o símbolo à explicação lógica" (BECCARI 2012, p. 216).

O símbolo possui essa característica de relacionar o significado com a forma. Ele é, portanto, um "articulador" entre um sentimento e a expressão deste sentimento. Através da articulação simbólica, gera-se o símbolo que verbaliza, toma forma, da expressão de uma experiência. Beccari (2012, p. 
219) entende os símbolos como a própria "projeção de todos os aspectos da natureza humana nas coisas que as cercam".

Passa-se então, a tentar entender como essa dimensão simbólica que pode ser representada por um símbolo, articulado no nível do psíquico, auxilia no processo de design de móveis planejados. Utiliza-se a técnica de Imaginação ati$v a$, desenvolvida por Jung e adaptada ao design por Beccari para aproximar, basicamente da tentativa de utilizar e interagir com as imagens que afloram à nossa mente (imaginário), para encontrar soluções criativas com interação consciente do processo. (BECCARI 2012, p. 343).

O regime da imaginação ativa consiste em quatro etapas, descritas na figura 03. Algo a se considerar é que, proporcional a intensidade e a recorrência nas experiências simbólicas de cada indivíduo, será o efeito, sobre este indivíduo.

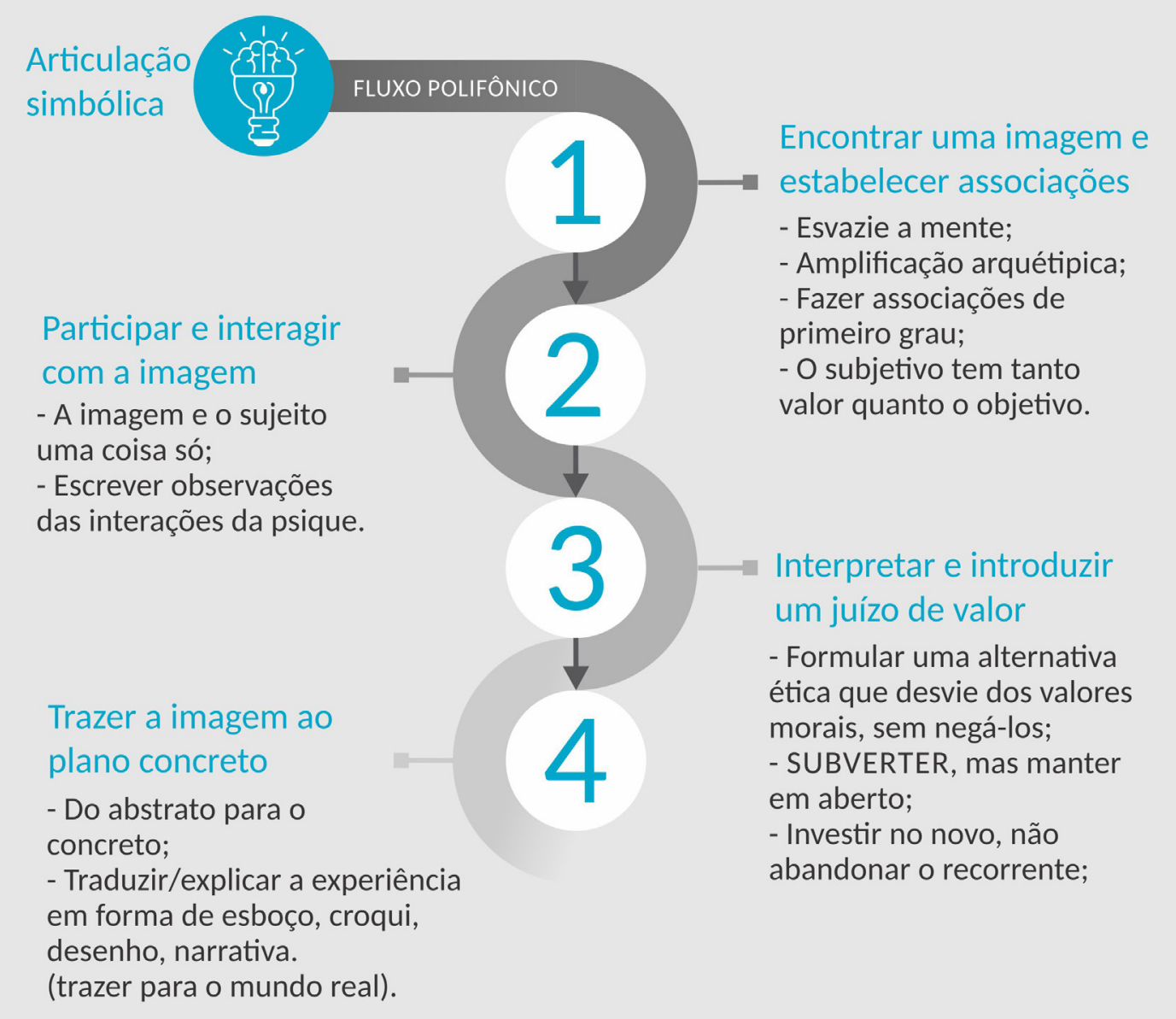

Figura 3: Imaginação Ativa. Fonte: Adaptado de Beccari (2012) pela autora, 2018. 
As etapas da técnica, representada pela figura 03, podem ser relacionadas com o móvel planejado da seguinte forma:

1) Encontrar uma imagem e estabelecer associações: esta etapa consiste em fugir de ideias preconcebidas, buscando uma novidade. As referências que alimentarão esta etapa podem vir de diversas fontes, carga acadêmica, experiência pessoal, observação e obviamente diálogo com o cliente. Todas essas fontes gerarão uma infindável lista de associações e inspirações, neste momento é importante estabelecer um dinamismo simbólico que permita dar sentido a uma experiência simbólica. Ressalta-se que é necessário permitir que essas "associações" ressoem imagens livremente, recomenda-se que o designer anote "qualquer coisa". Não estamos tratando aqui, de um processo de brainstorm de ideias, pois este tem como objetivo fazer associações das associações. Entretanto, na imaginação ativa, o objetivo é fazer infinitas associações sempre voltando à imagem inicial (BECCARI, 2012).

2) Participar e interagir com a imagem: este momento serve para deixar a imaginação agir. A imagem e o sujeito são uma coisa só. É como se construísse conscientemente um sonho e nele se manipulasse as associações dirigindo-as a relações diretas com a intenção projetual (BECCARI, 2012).

3) Interpretar e introduzir um juízo de valor: após a idealização de uma imagem, cabe ao designer, "formular uma alternativa ética que desvie de certos valores morais, sem, contudo, negá-los". Trata-se desse ponto da seguinte forma: a ideia é subverter o que for recorrente, evitando distanciamento da associação inicial, formulando algo novo. Deve-se escolher a interpretação inédita, que enfatize algo já conhecido, que não seja uma solução definitiva e que não esteja muito distante da imagem vigente (BECCARI, 2012).

4) Trazer a imagem ao plano concreto: essa etapa consiste em "encarnar" as imagens concebidas no pensamento, pela elaboração de esboços, desenhos, modelos e composições diversas, em algo físico (BECCARI, 2012). 
A adaptação descrita é uma tentativa de aproximar a teoria da prática. Estes itens narrados devem direcionar o profissional da área de móveis planejados a rever seu desenvolvimento de projeto com um olhar mais reflexivo e emocional.

\section{CONSIDERAÇÕES FINAIS}

As discussões abordadas neste artigo permitem algumas considerações e conclusões acerca do processo de criação de projeto de móveis planejados modulados. Ao longo deste trabaIho, foi realizada uma reflexão sobre o processo de criação do projeto de móveis planejados. Para esse entendimento, utilizaram-se os conceitos e métodos de interpretação e articulação simbólica dos autores Thompson e Beccari. Foi possível, a partir dos conceitos e métodos estudados, propor um passo a passo aplicado ao processo de criação do móvel planejado, na tentativa de melhorar as condições do designer como articulador na interpretação, explicação e significação de seus projetos.

O passo a passo metodológico proposto por este trabaIho não tem a pretensão de ser a solução total e final, mas sim um ponto de vista de uma entre tantas possíveis pesquisas. Entende-se ainda que, dependendo do caso, esta pesquisa pode ser aplicada no processo de criação de móveis planejados, ou ainda aperfeiçoada com a adição da experiência ou estudos de outros designers.

A conclusão que se pode chegar - quanto ao emprego do método segundo a perspectiva de vivencia de mercado da autora - é de que no instante em que se aplica a Imaginação Ativa com o intuito de interpretar e explicar de forma consciente durante o processo de criação, aberturas não convencionais de significação surgirão para qualificar o projeto final.

Uma consideração importante acerca de como a aplicação do método proposto aconteceria no mundo real, no cotidiano dos profissionais que atuam nas lojas que comercializam o móvel planejado modulado, é de que o método é totalmente realizável. Essa presunção é feita, pela projeção da execução deste trabalho na experiência de mercado que 
a autora possui. No entanto, a comprovação dessa afirmação fica a cargo de pesquisas futuras a campo, as quais não foram viáveis neste trabalho.

Por fim, conclui-se que, apenas em levantar-se o questionamento sobre as formas de interpretação e significação no processo de projeto de ambientes domésticos, já mostra um encaminhamento diferente aos costumes que se vivencia na atualidade. Com a contribuição desta pesquisa salienta-se que as experiências e anseios dos usuários sejam contemplados, dispara-se uma reforma nos parâmetros dos processos criativos voltados ao projeto de móveis planejados modulares.

\section{REFERÊNCIAS BIBLIOGRÁFICAS}

BECCARI, Marcos Namba. Articulações simbólicas: uma filosofia do design sob o prisma de uma hermenêutica trágica. 2015. Tese (Doutorado em Educação) - Faculdade de Educação, Universidade de São Paulo, São Paulo, 2015. doi:10.11606/T.48.2016. tde-09092016-150330. Acesso em 28 de mai. 2018.

BROWN, Tim. Design thinking: uma metodologia poderosa para decretar o fim das velhas ideias. Tradozido por Cristina Yamagami. Rio de Janeiro: Elsevier, 2010.

COLLET, Iara Barata; DISCHINGER, Maria do Carmo Torri; KINDLEIN JNR., Wilson. Desenvolvimento De Texturas Como Fatores De Design Emocional. In: DAMAZIO, Vera; MONT'ALVÃO, Claudia. Design

Ergonomia e Emoção. Rio de Janeiro: Mauad X, 2008.

GALINARI, Rangel; MORGADO, Ricardo Rodrigues; TEIXEIRA JUNIOR, Job Rodrigues. A competitividade da indústria de móveis do Brasil: situação atual e perspectivas. Publicado por BNDS Setorial 37, p.227-272, 2013. 
GORINE, Ana Paula Fontenelle. A indústria

de móveis no Brasil (Leitura Moveleira

2).Curitiba: Alternativa Editorial, 2000.

LÖBACH, Bernd. Designindustrial: bases para a

configuração dos produtos industriais. Traduzido por

Freddy Van Camp. São Paulo: Edgar Blücher, 2001.

NORMAN, Donald A. O Design Emocional: por

que adoramos (ou detestamos) os objetos do

dia-a-dia. Rio de Janeiro: Ed. ROCCO, 2008.

OSTROWER, Fayga. Criatividade e processos

de criação. $5^{a}$ ed. Petrópolis: Vozes, 1986.

THOMPSON, John. B. Ideologia e Cultura Moderna.

9a ed., Petrópolis: Editora Vozes, 2011. 